Revista da Universidade Estadual de Alagoas/UNEAL e-ISSN 2318-454X, Ano 12, Vol. 12 (4), outubro/dezembro (2020)

\title{
Record of the black aphid Aphis craccivora (Hemiptera: Aphididae) (Koch, 1854) in cowpea and fava bean plants in a greenhouse
}

\section{Registro do pulgão preto Aphis craccivora (Hemiptera: Aphididae) (Koch, 1854) em plantas de feijão caupi e feijão-fava em casa de vegetação}

\author{
Rodrigo Almeida Pinheiro ${ }^{(1)}$; Maria Jéssica dos Santos Cabral ${ }^{(2)}$; Rubens Pessoa de Barros ${ }^{(3)}$; \\ Taynara Alves de Sousa ${ }^{(4)}$; Daniel Rocha Santos ${ }^{(5)}$; Willian Cleisson Lopes de Souza. \\ ${ }^{(1)}$ ORCID: 0000-0001-5642-5065; Mestrando em Produção Vegetal; Universidade Federal dos Vales do \\ Jequitinhonha e Mucuri; \\ ${ }^{(2)}$ ORCID: 0000-0002-0081-566X; Mestranda em Produção Vegetal; Universidade Federal dos Vales do \\ Jequitinhonha e Mucuri; E-mail: jessicacabral810@gmail.com. \\ ${ }^{(3)}$ ORCID: 0000-0003-0140-1570; Professor do Departamento de Ciências Biológicas da Universidade Estadual \\ de Alagoas/Campus I; E-mail: pessoa.rubens@gmail.com. \\ (4) ORCID: 0000-0003-1934-7605; Universidade Estadual de Alagoas; graduanda em ciências biológicas; E-mail: \\ taynara.sousa1298@gmail.com. \\ ${ }^{(5)}$ ORCID: 0000-0002-6885-0824; Universidade Estadual de Alagoas; graduando em ciências biológicas; E-mail: \\ danielrocha-100@outlook.com. \\ ${ }^{(1)}$ ORCID: 0000-0001-8145-8977; Mestrando em Produção Vegetal; Universidade Federal dos Vales do \\ Jequitinhonha e Mucuri; willian22292@gmail.com.
}

E-mail do autor correspondente: rodrigo6450@gmail.com

Resumo - O pulgão preto do feijoeiro Aphis craccivora (Hemiptera: Aphididae) (Koch, 1854) é considerado uma praga polífaga, mas possui preferência por leguminosas. Com base nisso, objetivou-se com este estudo registrar a presença de A. craccivora em plantas de Vigna unguiculata e Phaseolus lunatus em casa de vegetação. O monitoramento e registro dos afídeos em plantas de $V$. unguiculata e Phaseolus lunatus foi realizado entre o período de dezembro de 2018 a março de 2019 em casa de vegetação, onde foram registrados ataques em plantas de $V$. unguiculata desde a fase fenológica V4 até o final do ciclo da cultura, causando danos como encarquilhamento de frutos devido a sucção de seiva. Em relação a $P$. lunatus, o registro de ataque foi observado no final do ciclo da cultura, onde não se observou danos às plantas e diminuição de sua produtividade. Por tanto, pode-se afirmar que em casos de infestação de $A$. craccivora em casa de vegetação, plantas de $V$. unguiculata estão mais suscetíveis e com maior propensão de danos e redução em sua colheita.

Palavras-chave: Afídeos. Leguminosas. População.

Abstract - The black aphid of the bean Aphis craccivora (Hemiptera: Aphididae) (Koch, 1854 ) is considered a polyphagous pest, but has a preference for legumes. Based on this, the objective of this study was to record the presence of black aphid A. craccivora in plants of Vigna unguiculata and Phaseolus lunatus in greenhouse. The monitoring and recording of aphids in plants of $V$. unguiculata and $P$. lunatus was performed out between December 2018 
Revista da Universidade Estadual de Alagoas/UNEAL e-ISSN 2318-454X, Ano 12, Vol. 12 (4), outubro/dezembro (2020)

and March 2019 in a greenhouse, where attacks on plants of $V$. unguiculata were recorded from the phenological phase V4 until the end of the culture cycle, causing damage fruit embodying due to sap suction. Regarding $P$. lunatus, he attack record was observed at the end of the crop cycle, where observed decrease productivity and no damage to the plants. Therefore, it can be affirmed that in cases of infestation of A. craccivora in a greenhouse, plants of $V$. unguiculata are more susceptible and with a greater propensity for damage and reduction in their harvest.

Keywords: Aphids. Legumes. Population.

\section{Introdução}

Os pulgões são insetos pequenos, com aproximadamente 1,87 a $2,10 \mathrm{~mm}$ de comprimento, a coloração varia do amarelo claro ao preto brilhante, possuem antenas mais longas que o corpo, com corpo ovalado, e apresentando no abdome, dois apêndices tubulares laterais chamados sifúnculos e um central chamado de codícola (ALI et al., 2001; GALLO et al., 2002).

O pulgão preto Aphis craccivora é considerado uma das principais pragas de leguminosas nos continentes Africano, Americano e Asiático (RAKHSHANI, 2005). Uma vasta quantidade de leguminosas podem ser hospedeiras do A. craccivora, mas a praga não é restrita apenas para a família Fabaceae (JABA et al., 2010).

A capacidade reprodutiva do A. craccivora nas condições climáticas do Brasil ocorre exclusivamente por partenogênese telítoca, onde as fêmeas adultas produzem somente ninfas fêmeas. O período ninfal é de aproximadamente 7 dias, no qual são verificados 4 instares (ALI et al., 2001; GALLO et al., 2002). O período para atingir a fase adulta geralmente é de 3 a 5 dias, onde são produzidos descendentes diariamente, e os insetos adultos podem viver, aproximadamente, 15 dias (MUÑIZ; PEÑA-MARTÍNEZ, 1992).

Quanto à interferência dos fatores abióticos no ciclo biológico, o aumento ou diminuição populacional das diferentes espécies de afídeos está relacionado diretamente às oscilações de temperatura, precipitação e condições nutricionais das plantas hospedeiras (ROBERT, 1987).

Com base ao que foi exposto, objetivou-se com este estudo registrar a presença do pulgão preto $A$. craccivora em plantas de feijão caupi (Vigna unguiculata) e feijão fava (Phaseolus lunatus) em casa de vegetação.

\section{Material e métodos}

O monitoramento de registro e ocorrência dos afídeos em plantas de $V$. unguiculata e Phaseolus lunatus foi realizado entre o período de dezembro de 2018 a março de 2019 na casa de vegetação do tipo capela, presente nas instalações da Universidade Estadual de Alagoas, Campus I, localizada no município de Arapiraca, situada nas coordenadas geográficas: $9^{\circ} 75^{\prime}$ $25^{\prime}$ ' S com latitude de $36^{\circ} 60^{\prime} 11^{\prime \prime}$ W longitude. O clima da região é classificado como As', determinando clima tropical e quente segundo a classificação de Köppen e Geiger (2006). 


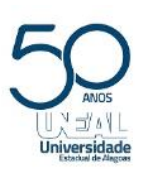

\section{Revista Ambientale}

Revista da Universidade Estadual de Alagoas/UNEAL e-ISSN 2318-454X, Ano 12, Vol. 12 (4), outubro/dezembro (2020)

\section{Resultados e discussão}

O processo de infestação iniciou-se em plântulas de $V$. unguiculata na fase fenológica V4 (figura 1), à medida que as plantas se desenvolveram, os botões florais e flores foram infestados (figura 2 (BERBERET et al., 2009). Em frutos infestados pôde-se verificar o encarquilhamento pela sucção de seiva pelos afídeos (figura 3) (SILVA et al., 2005). De acordo com Santos e Quinderé (1988), esse inseto ocorre em toda a região nordeste e podem infestar brotos terminais e pecíolos e folhas.

Figura 1. Registro de afídeos (A. craccivora) em plântulas de feijão caupi (V. unguiculata) em fase fenológica V4.

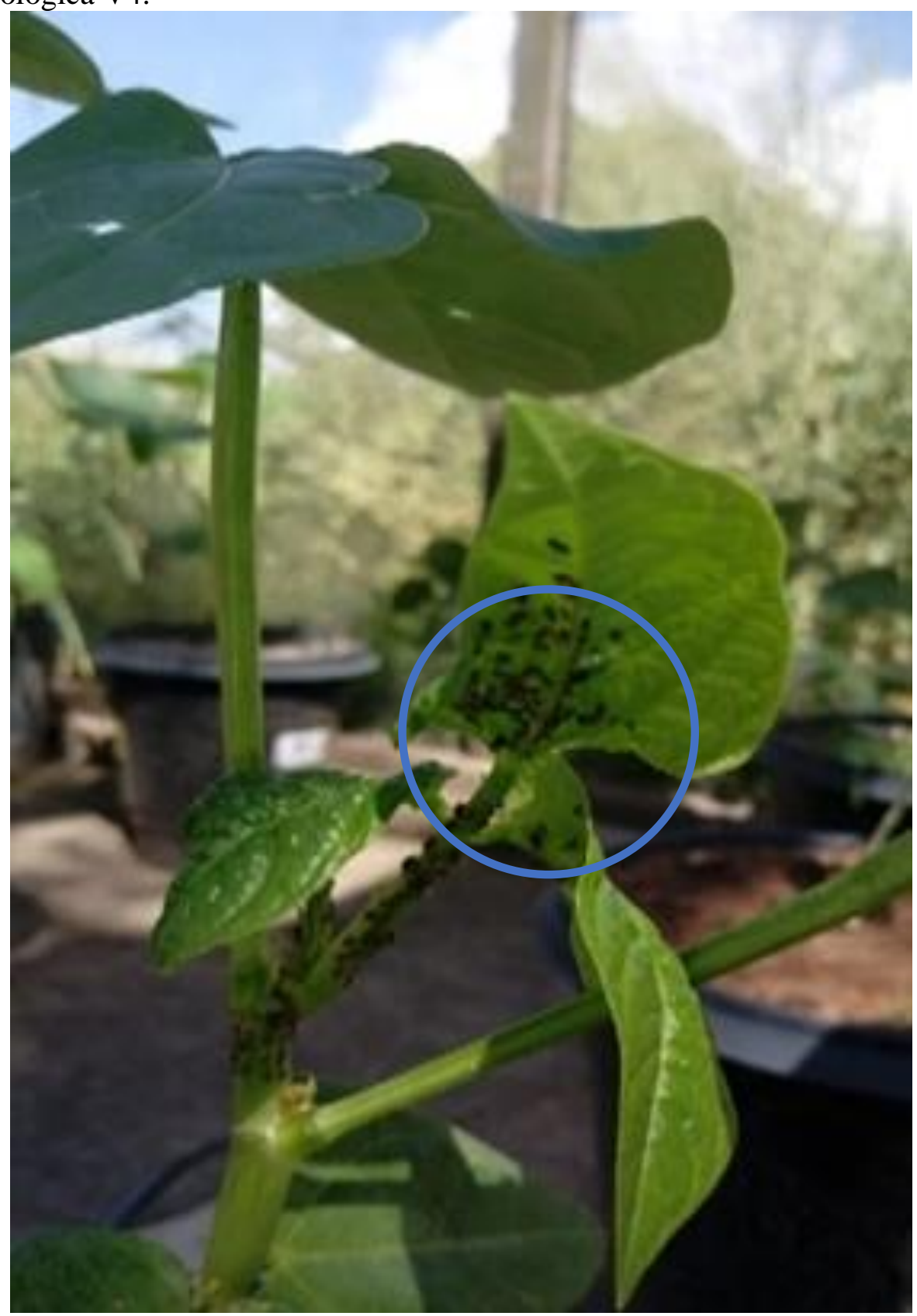

Fonte: arquivos do autor. 


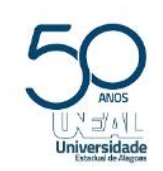

\section{Revista Ambientale}

Revista da Universidade Estadual de Alagoas/UNEAL e-ISSN 2318-454X, Ano 12, Vol. 12 (4), outubro/dezembro (2020)

Figura 2. Registro de A. craccivora em botões florais e frutos de $V$. unguiculata.

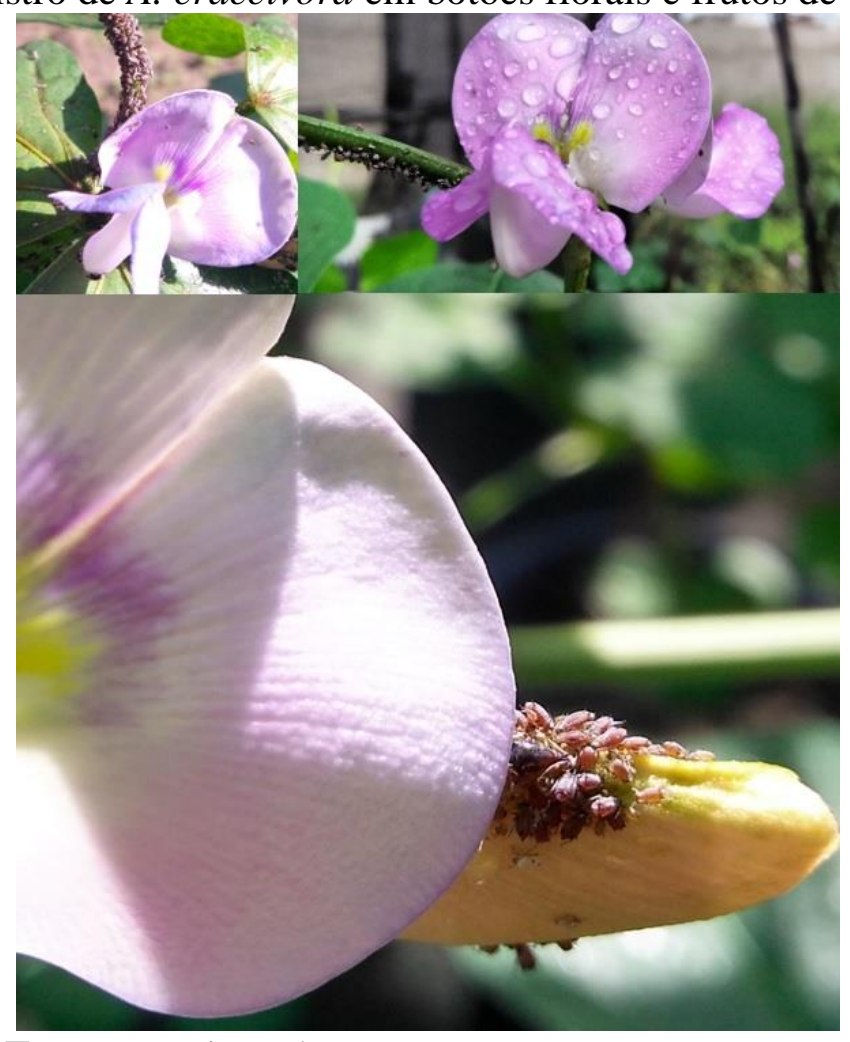

Fonte: arquivos do autor.

Figura 3. Fruto infestado (a) e fruto encarquilhado (b) de $V$. unguiculata por sucção de $A$. craccivora.
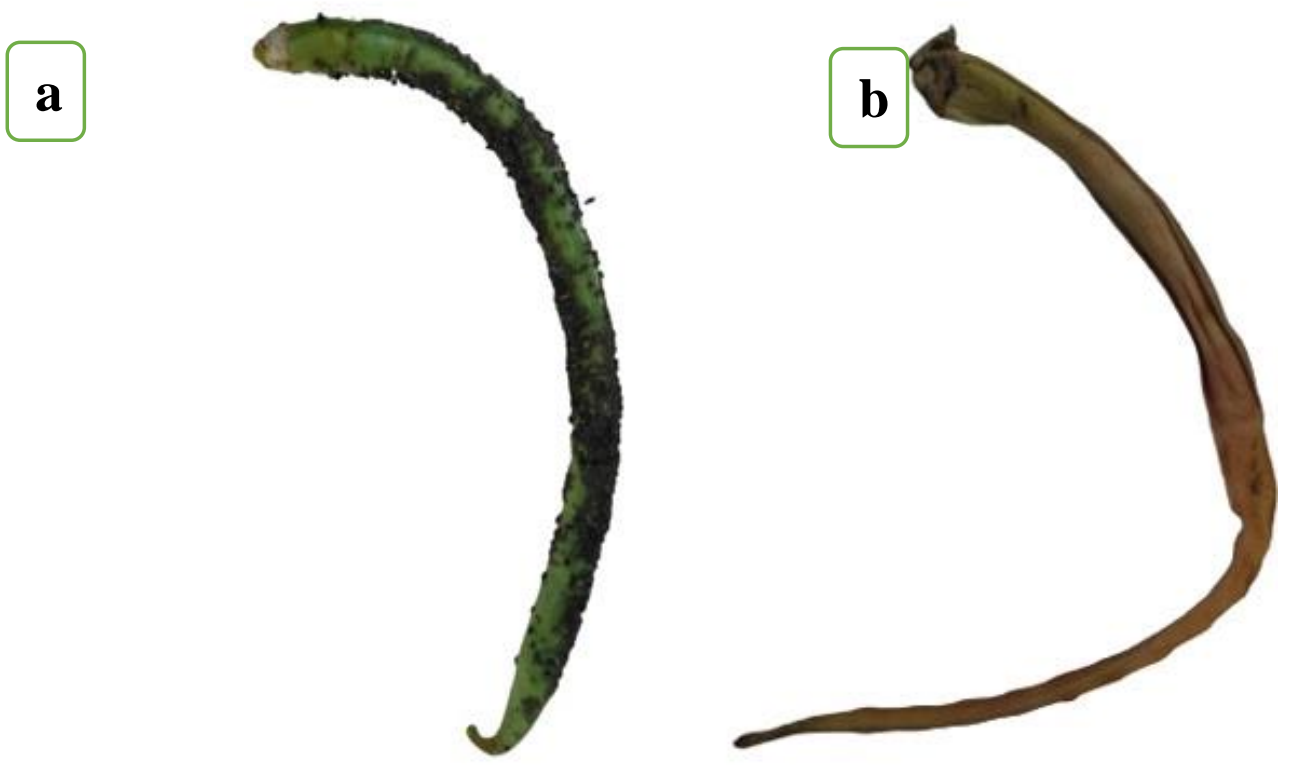

Fonte: arquivos do autor. 
Revista da Universidade Estadual de Alagoas/UNEAL e-ISSN 2318-454X, Ano 12, Vol. 12 (4), outubro/dezembro (2020)

Foi registrado a ocorrência de A. craccivora nos folíolos em $P$. lunatus dentro da casa de vegetação (Figura 4), porém, a ocorrência foi somente na fase 4 onde as plantas estavam com aproximadamente 70 dias, mas não foram registrados danos aos botões florais e frutos. Assim como o $V$. unguiculata, A. craccivora também já foi registrado em $P$. lunatus e Vieira (1992) relatou que existem poucos estudos sobre insetos associados ao P. lunatus. A. craccivora pode oferecer riscos e destaca por ter muito potencial para danificar colheitas.

Figura 3. Registro de A. craccivora em plantas de $P$. lunatus.

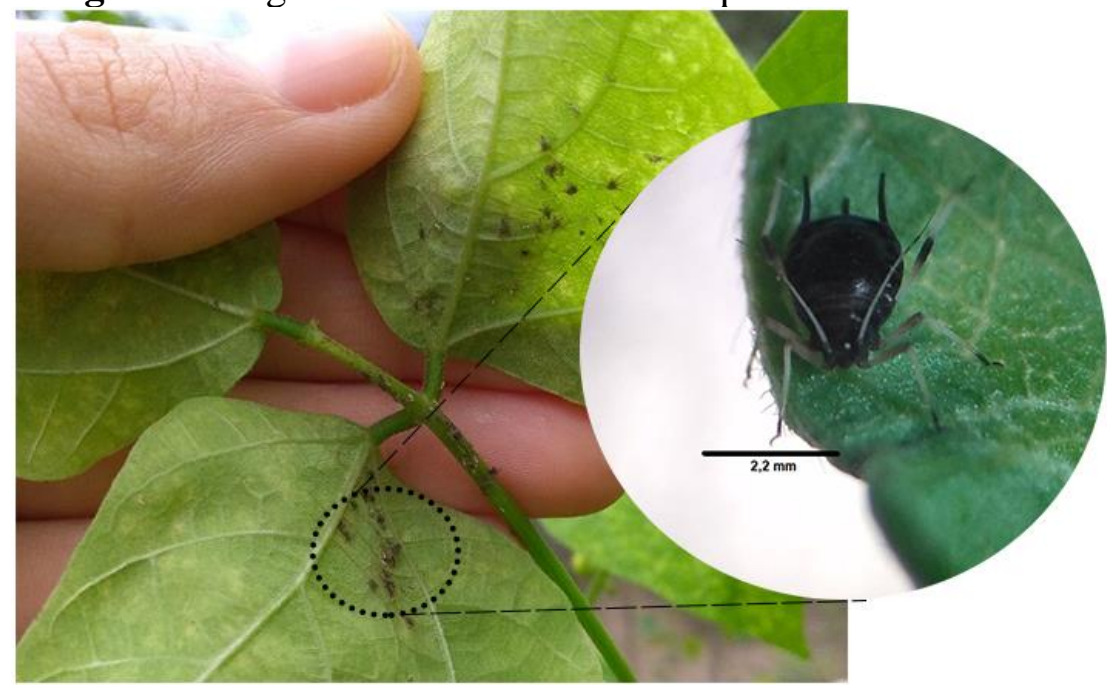

Fonte: arquivos do autor.

\section{Considerações finais}

Pode-se afirmar que em casos de infestação de A. craccivora em casa de vegetação, plantas de $V$. unguiculata estão mais suscetíveis e com maior propensão de danos e redução em sua colheita.

\section{Agradecimentos}

Ao grupo de estudos ambientais e Etnobiológicos - GEMBIO.

\section{Conflito de interesses}

Os autores deste manuscrito não declararam conflitos de interesse. 
Revista da Universidade Estadual de Alagoas/UNEAL e-ISSN 2318-454X, Ano 12, Vol. 12 (4), outubro/dezembro (2020)

\section{Referências}

ALI, A. M.; SALMAN, A. M. A. Some biological aspects of the cowpea aphid, Aphis craccivora Koch, Homoptera: Aphididae on faba bean. Assiut Journal of Agricultural Sciences (Egypt), 2002.

BERBERET, R. C.; GILES, K. L.; ZARRABI, A. A.; PAYTON, M. E. Development, reproduction, and within-plant infestation patterns of Aphis craccivora (Homoptera: Aphididae) on alfalfa. Environmental entomology, v. 38, n. 6, p. 1765-1771, 2009.

BUJANOS, M. R.; PEÑA-MARTÍNEZ, R. Áfidos transmisores de virus fitopatógenos. Urias-MC; R. Rodríguez-M. y T. Alejandre A. (Eds). Áfidos como vectores de virus en México, v. 1, p. 76-90, 1992.

CARVALHO, L. D., BUENO, V. H. P., \& MARTINEZ, R. P. Levantamento de afídeos alados em plantas hortícolas em Lavras-MG. Ciência e Agrotecnologia, v. 26, n. 3, p. 523$532,2002$.

FREIRE FILHO, F. R.; LIMA, JA DE A.; RIBEIRO, V. Q. Feijão-caupi: avanços tecnológicos. Brasília: Embrapa Informação Tecnológica, 2005.

GALLO, D.; NAKANO, O.; NETO, S. S.; CARVALHO, R. P. L.; BATISTA, G. C.; BERTI FILHO; E.; ... MARCHINI, L. C. Entomologia agrícola. Piracicaba, FEALQ, 920p. Macedo, Macedo, Campos, Novaretti e Ferraz, v. 158, 2002.

JABA, J.; HASEENA, B.; TRIPATHY, S.; HOSAMANI, A. C.; AMARESH, Y. S. Olfactory response of cowpea aphid, Aphis craccivora Koch, to host odours and population of conspecifics. Journal of Biopesticides, v. 3, n. 1, p. 405, 2010.

LOPES, A. C. A.; GOMES, R. L. F.; ARAÚJO, A. S. F. A cultura do feijão-fava no MeioNorte do Brasil. Teresina: EDUFPI, 2010.

PEREIRA, P. R. V. S.; SALVADORI, J. R.; LAU, D. Distinção necessária. Revista Cultural, 2009. 10 p. (Caderno Técnico 4).

RAKHSHANI, E.; TALEBI, A. A.; KAVALLIERATOS, N. G.; REZWANI, A.; MANZARI, S.; TOMANOVIĆ, Ž. Parasitoid complex (Hymenoptera, Braconidae, Aphidiinae) of Aphis craccivora Koch (Hemiptera: Aphidoidea) in Iran. Journal of Pest Science, v. 78, n. 4, p. 193-198, 2005.

ROBERT, Y. Dispersion and migration. Aphids: their biology, natural enemies, and control, v. 2, p. 299-314, 1987.

SANTOS, J. H. R.; QUINDERÉ, M. A. W. Distribuição, importância e manejo das pragas do caupi no Brasil. In: ARAÚJO, J. P. P.; WATT, E. E. (Org.) O Caupi no Brasil. Brasília: IITA/EMBRAPA, 1988, p. 605-658. 
Revista da Universidade Estadual de Alagoas/UNEAL e-ISSN 2318-454X, Ano 12, Vol. 12 (4), outubro/dezembro (2020)

SINGH, S. R. Cowpea cultivars resistant to insect pests in world germplasm collection. Trop Grain Legume Bull, 1977.

TEÓFILO, E. M.; DUTRA, A. S.; PITIMBEIRA, J. B.; DIAS, F. T. C.; DE SOUSA

BARBOSA, F. Potencial fisiológico de sementes de feijão caupi produzidas em duas regiões do Estado do Ceará. Revista Ciência Agronômica, v. 39, n. 3, p. 443-448, 2008.

VIEIRA, R.F. A cultura do feijão-fava. Informe Agropecuário, Belo Horizonte, v.16, n.174, p.30-37, 1992. 